\title{
WAYS OF THINKING ABOUT EDUCATION IN EUROPE
}

\author{
António Nóvoa \\ (University of Lisbon)
}

A decade ago, when I first began addressing issues of education policy in Europe, I was obliged to justify my inquiry ${ }^{1}$. Why should one speak of these matters if there is no unified European education policy? Why speculate on topics that are the full responsibility of each Member State? Although I respect my interlocutors, our conversations failed to acknowledge one important link in the analysis of education policies. We need a closer understanding of the European layer. This is the collective education policy defined, individually and jointly, by decision-makers at all levels in Europe - from local to national, from regional to global - that establishes a basis for a European education.

Today, no justification is needed to discuss $W$ ays of Thinking about Education in $E_{\text {urope }}^{2}$. In a short time, important changes took place in the so-called "European educational space", opening to new perceptions of intertwined and overlapping levels of policy formation. A recent statement by Anders Hingel, head of the education policy unit at the European Commission, clearly stated: "What is presently happening in co-operation in the field of education tells us, that not only is a European Space of Education in its making, common principles of education are being agreed upon between Member States, leading logically to a European Model of Education" (2001, p. 4).

Furthermore, there has been a significant development in the recent and wide growth of European studies. A quick search on the Internet displays thousands of titles that try to explain this new "political entity". It is true that they mainly address economics, law, and the social and political sciences; education remains an understated topic. Regardless, such studies do provide a theoretical ground to enlighten educational issues and avoid "non-overt debate" and "semi-clandestine policy" (Nóvoa, 2000), which had characterized European Union attitudes and decisions for a long time.

\footnotetext{
${ }^{1}$ The chapter was finished during a stay as Visiting Professor at Teachers' College (Columbia University, New York), due to a grant given by the Fulbright Foundation. I am indebted to several colleagues who commented on the first drafts of this chapter, mainly to Thomas Popkewitz, Francisco Ramirez and Stephen Stoer. I want also to express my gratitude to Kimberly Ochs, Tali Yariv-Mashal and Audrey Bryan who helped me in the final revision of the text.

${ }^{2}$ I am mainly referring to the European Union, but use some examples (e.g. the Bologna Declaration) that go beyond institutional frontiers.
} 
- In a brief introduction, I will outline the main steps in the formulation of a set of norms and regulations that constitute a European educational policy;

- In the first section, I will criticize three "influences" that have lead to current ways of thinking - the agenda setting by the media, the new "planetspeak", and the excesses of past and future - and reveal how they define the educational debate in the European Union;

- Using this trilogy, in the second section I will analyze a set of documents recently issued by the European Union ("Brussels") in an attempt to interpret the main tenets of the European Educational Policy, as they relate to issues of employability, comparability, and mobility.

- Finally, I will illustrate the arguments raised throughout this chapter by using the Bologna process, and argue for the need to rethink the role of research in reference to the limits of current ways of thinking about Education in Europe.

\section{PaTHS TOWARDS A EUROPEAN EDUCATIONAL POLICY: A BRIEF INTRODUCTION}

A course of action to formulate a set of norms and regulations of a European Educational Policy is well established. It has been, and will remain, a very complex process, which began in 1971 at the first meeting of the Ministers of Education. The last document approved by the Stockholm European Council, The concrete future objectives of education and training systems (March 2001), continues to outline these steps.

Education has been one of the most contested arenas in Europe, not only due to its symbolic value in national imaginaries but also because of public resistance to a "common policy". The results of the Eurobarometer ${ }^{3}$ reveal that a majority of European citizens believe that the formulation of educational policies should remain at the level of each Member State. The European Union put forward some measures in education and training, but simultaneously reiterated in their literature, namely in the Treaties, that the formation of educational policies should remain at a national level. One of the first rules young historians are taught is to mistrust "sentences" written in successive laws or documents. In general, such reiteration merely highlights the gap between rhetorical statements and what actually happens. This helps us to understand the systematic reference, in the documents issued by Brussels, to the

\footnotetext{
${ }^{3}$ The Eurobarometer publishes results from various surveys and research instruments used to measure the "public opinion" on European issues (http://europe.eu.int/comm/public_opinion).
} 
action of the European Commission "within the limits of its powers", "while fully respecting the responsibility of the Member States", and "excluding any harmonization of the laws and regulations of the Member States".

Does this mean that there has been a harmonization of laws or a unification of educational systems? Not necessarily. Several studies, such as that by A. Green, A. Wolf and T. Leney, have shown that there is not, "any marked convergence in the details of policy formulation across countries, or in the actual structures and practices of education and training" (1999, p. 234). Yet, we cannot ignore the signs that are in front of us, such as the words written in the official document, The concrete future objectives of education and training systems: "While we must preserve the differences of structure and system which reflect the identities of the countries and regions of Europe, we must also recognize that our main objectives, and the results we all seek, are strikingly similar. We should build on those similarities to learn from each other, to share our successes and failures, and to use education together to advance European citizens and European society into the new millennium” $\left(2001, \mathbb{\int} 37\right)$.

In reality, from the middle of the 1980s, and especially in recent years, the programs and guidelines that have been implemented at the European level reflect a consensus of thought about education ${ }^{4}$. New ways of governing have been defined which have proven to be extremely attractive, and have tended to de-legitimize all alternative positions and dispositions. Of course, no country will abdicate a rhetoric affirming its "national identity". Yet, all countries are incorporating the same guidelines and discourses presented as the only way to overcome educational and social difficulties. The strength of these guidelines is seen in their acceptance by Member States with a "sense of inevitability". In the upcoming years we will invariably witness the deepening of this contradiction: national politicians will shout out loud that education is an exclusive matter for each Member State, as they adopt common programs and policies.

Allow me to describe an "episode" that is symptomatic of this situation. In 1998, the Portuguese Minister for Education gave vigorous statements to the press opposing the Sorbonne Declaration on the "harmonization of the European higher

\footnotetext{
${ }^{4}$ Within the past few years alone, over a hundred education and training documents have been produced, some of which are of vital significance: Green Paper European Dimension of Education (1993), White Paper Growth, Competitiveness, Employment (1994), White Paper Teaching and Learning: Towards the Learning Society (1995), Documents of the European Year of Lifelong Learning (1996), Green Paper Education-Training-Research: Obstacles to Transnational Mobility (1996), Study Group Report Accomplishing Europe through Education and Training (1997), Communication from the Commission Towards a Europe of Knowledge (1997), Report Learning for Active Citizenship (1998), Memorandum on Lifelong Learning (2000), European Report on Quality of School Education (2000), etc.
} 
education system". The minister said, "This is a dangerous step. We are beginning with a harmonization of the academic degrees, next we will move on to the duration of studies and the programs, and we won't know when to stop". Yet, he later concluded his press statement with a curious comment, "In fact, Portugal is in a comfortable position to criticize this homogenization given that our academic degrees are already set up in the way that this Joint Declaration outlines".

It is worthy to again quote the head of the education policy unit in Brussels, elaborating on the decisions taken during the Lisbon European Council, held in March 2000: "Since the very beginning of European co-operation in the field of education, Ministers of Education have underlined the diversity of their systems of education. The very reason why they met was in fact that their systems were diverse. Any mentioning of common denominators was considered of lesser importance and mainly used in national debates. The Lisbon conclusions break with this by asking the Ministers to concentrate their reflection on what is common. [...] The Lisbon conclusions implicitly give the Union the mandate to develop a common interest approach in education going beyond national diversities as can already be seen in the demand to Ministers of Education to debate common objectives of educational systems. This mandate will lead to an increase in the European dimension of national educational policies" (Hingel, 2001, pp. 15 \& 19).

My argument is that Europe functions like a regulatory ideal that tends to influence, if not organize, national policies. It is obvious that no "homogenization" will occur. Talk of the diversity of national education systems is almost a "tautology". Although, it will not cease tendencies towards defining common goals, similar strategies and, therefore, identical policies. Thus, it is no surprise that "knowledgebased policies" are about to form one of the four fundamental pillars of the Union's internal policies, as put forward in the Agenda 2000. The Education Council has also established a "rolling agenda", which is a prevailing and recurrent agenda on educational issues. European citizens are persuaded to accept these decisions through rhetoric in the media such as "A Europe of Knowledge is being created at high speed", or "In the field of education, Europe - a Europe of citizens - is on the move", and even the need to build "The European House of Education".

The complexity of the debate calls for more theoretical tools and approaches. It is useless to reproduce distinctions and dichotomies that cannot help raise new understandings. We must not look at this issue as a conflict between "national states" and "European institutions". This is not a zero-sum game, where giving more power to "Europe" will automatically lead to a weakening of the "nation-state", or viceversa; an arithmetical conception of power is totally inaccurate. One can also argue that, in several cases (e.g. Southern European countries), the participation in the 
European process has been the only way to re-legitimize states weakened by long periods of dictatorship. In fact, it is possible to look at the European Union as a political form that "strengthens the state", acknowledging that between its institutions and levels of decision the most powerful are the Member States and their representatives (Peterson, 2001). Furthermore, it is important not to forget that in most national states the local or regional authorities hold responsibility for the majority of educational decisions. No dualistic or simplistic analysis will allow us to understand such an intricate situation.

Another vain approach may be found in the obsession to name the "new political form" that is being constructed in Europe: Is it a Federation of nation-states? Union of states? Association of sovereign states? This nominalistic approach intends to fix and stabilize a form that can only be understood in its plasticity. Adopted by some political scientists working in the context of the so-called "European studies", these forms encircle us in a never-ending search for typologies and configurations (e.g. Hantrais, 2000; Wallace, 2001). Here, I will adopt a more theoretical and pragmatic perspective in this interpretation of the European educational debate.

\section{THREE “INFLUENCES" THAT LEAD TO CURRENT WAYS OF THINKING ABOUT EDUCATION IN THE EUROPEAN UNION}

Let me begin by explaining three overlapping and interconnected ways of thinking, which give rise to an undefined "magma" that is later transformed into a "raw discourse" about Europe. I will argue that they are present in texts and policies, and represent a vision to reconstruct the educational "space". I will begin by addressing the consequences of agenda setting by the media, then analyse the new "planetspeak" of the international expert's discourse and, finally, criticize the excesses of past and future in discussions about Europe.

\section{The agenda setting by the media}

The agenda setting by the media is one of the most significant "influences" in current

European debates $^{5}$

\footnotetext{
${ }^{5}$ I am referring to "agenda setting by the media" in the sense portrayed in theories of communication: "The power of the media to both heighten the importance of particular issues in public consciousness and to set the parameters of debate around these issues by framing them in such a way as to promote particular representations or responses as valid and legitimate, thereby excluding or marginalizing others" (Roscoe, Marshall \& Gleeson, 1995).
} 
- We are witnessing a spread of discourses that dramatize educational matters, imposing "solutions" through the structure of questions and portrayal of problems. Dressed in an impressive "moral conformity", there is an interesting unanimity in this debate, which is fueled by opposing pedagogy and educational theories, and uses hackneyed terminology such as rigor, efficiency, accountability, responsibility, autonomy, market, choice, customers, etc. As Pierre Bourdieu (1996) explains well, the "newspaper intellectuals" read each other's viewpoints, meet on a regular basis, frequent the same places and transform the media universe into a closed world where the logic of mutual choice reigns. This logic leads to an even more effective censuring and exclusion than that of a "central bureaucracy" given that it is invisible and legitimized by the rhetoric of freedom.

It is important to acknowledge two further consequences of the agenda setting by the media. The first one relates to the adoption of an "instant democracy" based on a regular estimation of public opinion. The "democratic deficit", denounced for instance by Jürgen Habermas (2001), obliges European Union officials to an overwhelming exercise of auto-justification. It leads to conceptions confined by the limits of a new doxa, and also to institutional activism at the European level.

The second consequence is connected to the "society of the spectacle", as it was first characterized by Guy Debord (1994). In a recent work, Michael Hardt and Antonio Negri elaborated on the ideas of this French philosopher, and argued that, "the spectacle destroys any collective form of sociality and at the same time imposes a new mass sociality, a new uniformity of action and thought" (2000, pp. 321-322). Addressing the media manipulation of public opinion and political action, they maintain that, even if there is no single locus of control, "the spectacle functions as if there were such a point of central control" (2000, p. 323). In fact, "surveillance" and "spectacle" are not divergent positions. On the one hand, surveillance is exercised through an exposure to media, which creates new forms of auditing and controlling. On the other hand, spectacle is subject to rules of surveillance (measures, indicators, rates, etc.) that define its own characteristics (Nóvoa, 2001).

This background is obviously not conducive to serious thinking about education. Intellectual reflection cannot be done on the spur of the moment and without suitable research tools, techniques and methods. We are confronted with the dissemination of set ideas, intended to be neutral and consensual, that occupy the public educational space, but ignore or devalue all other contributions. This "uniformity of action and thought" tends to hide ideological stances as well as create the illusion of a single course for educational issues. I will argue that one of the first tasks for educational research is to deconstruct these "evidences".

The new planetspeak of the international expert's discourse 
A second tendency, which partly overlaps the previous one, concerns the figure of the expert and his/her mobilization in a manner that transcends national boundaries. This movement of experts creates and circulates international discourse, without structural roots or social locations. We are faced with a strange "worldwide bible" whose vocabulary, of unknown origin, is on the tip of every tongue: globalization and flexibility, new economy and governance, underclass and exclusion, zero tolerance and multiculturalism, etc. (Bourdieu, 2000). In order to spread these concepts around the world, they need to be transformed into topoi, that is, banalities universally accepted to become truth that do not need to be questioned. Such topoi support a reasoning that represents no author. They are then transformed into magic concepts; magic, because they are seen as "the solution" for most of the problems.

In recent years, governance has become one of these magic concepts applied to reform European institutions. The European Commission is addressing the "need for urgent action to adapt governance under the existing treaties" to contend with "disenchantment" and "alienation" from the Union's work

\footnotetext{
${ }^{6}$ I am quoting the White Paper European Governance, issued by the European Commission in 2001, where the following definition is given: "Governance means rules, processes and behaviour that affect the way in which powers are exercised at European level, particularly as regards openness, participation, accountability, effectiveness and coherence" (2001, p. 5).
} 
- Political scientists are trying to grasp this concept, even if their attempts are often more confusing than elucidating. That is the case, for instance, of Philippe Schmitter: "Governance is not a goal in itself, but a means for achieving a variety of goals that are chose independently by the actors involved and affected" (2001, p. 8); "Governance is a method/mechanism for dealing with a broad range of problems/conflicts in which actors regularly arrive at mutually satisfactory and binding decisions by negotiating and deliberating with each other and cooperating in the implementation of these decisions" (2001, p. 8). With these "definitions" in mind, he arrives at the following conclusion: "My (untested) presumption is that, if the EU were to elaborate and defend such principles and, then, design its arrangements of governance accordingly, it would improve their legitimacy" (2001, p. 10).

"Legitimacy" is the word one should retain. This new approach to European affairs is, in fact, a strategy to move the discussion away from matters of government (habited by citizens, elections, representation, etc.) and place it in the more diffused level of governance (habited by networks, peer review, agreements, etc.). The idea that the "European Union is a polity that operates with multilevel governance and functions as a regulatory state" lies beyond these assumptions (Roberts \& Springer, 2001, p. 2). Despite the numerous efforts to define governance, one must recognize that the popularity of the concept resides in its imprecision and fluidity, allowing different uses and understandings. Thus, it is without surprise that we see another concept being mobilized for the same purpose: soft-regulation. Curiously enough, it is often defined through a series of related terms and expressions: contract culture, flexible frameworks, benchmarking, target-setting, auditing, open-ended processes, etc. (Sisson \& Marginson, 2001). In both cases, we are witnessing reconstruction of the political field.

Benchmarking practices, initially used in management, are nowadays one of the most successful tools for implementing governance policies. Keith Sisson and Paul Margison consider that benchmarking offers a way to achieve co-ordination without "apparently" (sic) threatening national sovereignty. They quote the President of the European Commission in a speech to the European Round Table of Industrialists who said, "We are all benchmarkers now", concluding with the following comment: "Increasingly, rather than legal regulation and collective bargaining being the main engines of Europeanization, it is developments involving benchmarking that are to the fore. Indeed, it is no exaggeration to suggest that, in terms of EU policy making, benchmarking is acquiring quasi-regulatory status, raising major questions for theory and practice" (2001a, p. 2). In fact, one needs to look at "benchmarking" not as technique or method, but as a political position.

At the Lisbon European Council (March 2000), some of these discourses and 
practices have been put under the umbrella of the "open-method of coordination". Dermot Hodson and Imelda Maher argue that this "method offers a new approach to governance of the EU as heterarchical, decentred and dynamic process. It supports and radicalizes the principle of subsidiarity; offers an alternative to the treaty rules on enhanced co-operation; and addresses some of the legitimacy issues inherent in the EU' (2001, pp. 719-720). Their claim is that the European Union is an experimental process, and that our minds must be open to new political and social forms of organization. Nevertheless, these "approaches" are being constructed as the only solution to European problems, a solution that is defined by its flexibility and adaptability. Historians are well acquainted with the "gardening metaphor" that was employed by educators at the beginning of the $20^{\text {th }}$ century. It is not surprising to notice the rebirth of this metaphor as a way to illustrate EU politics: "gardening in the face of climate change, the turns of the seasons, the predators and the diseases that invade, as well as the changing tastes and fashions that influence garden design" (Olsen cit. in Wallace, 2001, p. 583). But once again, as in the former pedagogical illustration, the tools and the actions of the gardener are forgotten: to prune, to weed, do cut, etc. The metaphor loses its attractiveness and naïveté.

My argument is that this conceptual amalgamation creates the illusion of a common agenda, spreading worldwide definitions and principles that are relocated in each political context. If we treat discourses about educational reform as governing practices - in line with the works of Thomas Popkewitz (2000) - we realize the importance of these "ways of thinking". Then, it will be possible to consider how the rules, standards and styles of reasoning are also injunctions as to how individuals should speak, think, and act in the educational field. We are, indeed, faced with new ways of governing with significant consequences in each country, but also within the framework of the "European construction", as it is termed in Brussels. For this reason, I reiterate that one of the main tasks of comparative research is to break out of the limits imposed by these ways of thinking.

\section{The excesses of past and future}

This new turn of the century is rife with exaggerations and prophecies. In the case of the European Union, the excess of past and the excess of future both constitute part of the same "discursive formation". One imagines a "past" that legitimizes current European institutions, yet at the same time invents a "future" that gives support to political decisions. Discussion relates directly to issues of identity. The citizens are not evoked as a "whole", but as fragments where past and future are fused in the same movement to imagine the nation-Europe. It is possible to find a large quantity of works analyzing principles of citizenship in Europe, but most of them are 
caught in a dichotomy of thinking that opposes "fixed" and "multiple" identities. On the one hand, we find different, and often contradictory, critiques of supra-national citizenship that "encourages a form of politics in which citizens are managed and manipulated by distant, unaccountable and almost unfathomable powers" (Rabkin, 2001, p. 3). We also have critiques of cosmopolitan theories of citizenship, because the virtues required by republican citizens, "are likely to be cultivated only within national borders" (Smith, 2000, p. 5). On the other hand, there is a call for an integration of fragmented identities and a post-national collective identity: "a fluid collective identity to be constructed permanently" (Eder \& Giesen, 2001, p. 13). It is necessary to situate this debate as we redefine our concepts of time and space, and therefore, become aware of its historical dimension. Excesses of past and future will not help us to raise new understandings.

The excess of past manifests itself in grand and eloquent speech about tradition and the destiny of Europe. These accounts that are very active in the European context, sometimes infuse a mythical and unified vision of European "civilization". Other times, they focus more precisely on a heroic perspective of recent accomplishments, such as the White Paper on European Governance: "European integration has delivered 50 years of stability, peace and economic prosperity" (2001, p. 5). In fact, the excess of past can be conceived as "empty history", as it is called by Walter Benjamin (1999). He argues that history is the critical engagement of the present, producing collective memories available for scrutiny and revision. This is a totally different concept from nourishing nostalgic or unitarian narratives of the past to use as justification for present actions.

The excess of future manifests itself in recurring rhetoric about the "new millennium" and is patently evident in the strategic planning and prospective studies that are so much to the liking of the European Union. The announcement of the "learning society" or the "Europe of knowledge", in addition to other terms coined in Brussels, compose part of this "passion for the future", and very often translate to a deficit of the present. In fact, state attempts to control temporality have produced not only the "invention of tradition", as analyzed by Eric Hobsbawm (1990) in his historical treatment of nationalism, but also attempts to control interpretations of the future. An identical process is taking place at the European level, where considerable energy has been put into managing anticipation as well as historical memory. The main trend is towards creating "positive illusions" that nurture an unrealistically optimistic view of the future, "believing that it will bring what is personally or socially desirable rather than what is objectively likely" (Bennett, 2001, p. 194).

Inside European debates we need to understand politics of memory and forgetting, but also politics of prediction and forecasting. They establish relations to 
historical time through new configurations and fabrications in the dual sense of fictions and making. This explains why current tales about the European "soul" - a word that has become very popular - are again so powerful. Nevertheless, as Homi Bhabha (1990) has argued, the writing of the nation is not merely a unity but involves a "double time", as people are both historical "objects" who construct a memory of constituted historical origin, and the "subjects" of a process of signification through which redemption and reproduction occur. Furthermore - and this is very important in the writing of the nation-Europe - the production of new memories embodies forgetfulness as new feelings of attachment and identity inscribe anxieties and displacements. Then, the questions raised by Rogers Brubaker, take on a new meaning: "We should not ask what is a nation: but rather how is nationhood as a political and cultural form institutionalized within and among states? [...] What makes the nation-evoking, nation-invoking efforts of political entrepreneurs more or less likely to succeed?” (1996, p. 16).

It is almost redundant to stress that education and schooling are directly related to imaginaries and fabrication of identities. John Meyer, in a lecture on "Globalization and the Curriculum" (1999), showed that the reorientation of education towards global rather than national society involves shifts in curricular perspectives. He highlighted the edit to no longer mention the past of the school but to the replace it with the brave new future. Education is still a very powerful myth. It is extremely symptomatic that the two foundation stones of the mass schooling systems - the training of "efficient workers" and of "good citizens" - continue to be present in the European make-up. I will argue that we need to move from "geographical" forms of citizenship - as they have been discussed by authors such as Ernest Gellner (1983) or Anthony Smith (1991) - to an interpretation of new journeys and itineraries (by refugees, exiles, illegal aliens, migrant workers, intellectuals, etc.) that encourage nonterritorial forms of affiliation and solidarity. A perspective that intends to "replicate" national endeavors at a European level will not allow us to grasp an accurate understanding of a situation that needs to be analyzed in its own terms.

The three "ways of thinking" to which I just referred - the agenda setting by the media, the new planetspeak of the international expert's discourse, and the excesses of past and future - are present in the formulation and justification of European educational policies. In the second section of this chapter, I intend to develop this argument and suggest new analyses of the so-called "European educational space". I will try to show that these "ways of thinking" influence the construction of systems of reason and principles of action inside the educational field. I would like to suggest that we dedicate ourselves to an intellectual reflection of understanding Europe - the various Europes - in its complexity and diversity. The European present calls for a style of investigation that is modest: "It encourages an 
attention to the humble, the mundane, the little shifts in our ways of thinking and understanding, the small and contingent struggles, tensions and negotiations that give rise to something new and unexpected" (Rose, 1999, p. 11). I have no ambition to provide a total account of such a complex situation. However, I do not renounce to engage myself in an effort to open up the "repertoire of possibilities" for thinking about education in Europe.

\section{ANALYZING THE EUROPEAN EDUCATIONAL POLICY: EMPLOYABILITY, COMPARABILITY AND MOBILITY}

In the introduction, I provided a brief overview of the main documents and decisions that contributed to the building of a European educational policy. It is clear that an important change was taking place by the mid-1990s with the diffusion of texts such as the White Paper Teaching and Learning: Towards the Learning Society (1995) or the Study Group Report Accomplishing Europe through Education and Training (1997). These texts were very powerful in constructing ways of thinking and talking about education, but their "legal status" was relatively weak. In fact, the framework set out in articles 149 and 150 of the Treaty of the $\mathrm{EU}^{7}$ did not authorize the European Commission to go further in its intervention in the educational field. The ground was, however, being prepared for the decisive turn that took place by the year 2000 .

Several discussions and decisions led to the approval of the Agenda 2000, allowing subsequent discussions to include "knowledge-based policies" as the fourth pillar of the Union's internal policies. Meanwhile, the Education Council set up a "rolling agenda", with three priority themes: a) the role of education and training in employment policies; b) the development of quality education; and c) the promotion of mobility, including recognition of qualifications and periods of study. Taking another important step, the conclusions of the Lisbon European Council (March 2000) stated the following, "The European Council asks the Council (Education) to undertake a general reflection on the concrete future objectives of education systems, focusing on common concerns and priorities while respecting national diversity" ( $\mathbb{\Omega}$ 27). The door was opened to allow more overt intervention by the European Commission in the field of education.

\footnotetext{
${ }^{7}$ These articles were first included as articles 126 and 127 of the Treaty of Maastricht (1992), and were subsequently ratified as articles 149 and 150 of the Treaty of Amsterdam (1997).
} 
Thus, it is without surprise that European institutions during the years 20002001 approved an important set of documents. Furthermore, the Stockholm European Council (March 2001) asked the Education Council to present a detailed work program as follow-up to execute the objectives of education and training systems, including an assessment of their achievement at the national level, to be approved in 2002. There is no doubt that we are witnessing a profound change in European educational policy. Given this activity, my analysis will focus mainly in the materials issued during the last two years ${ }^{8}$. I will examine these documents through a triple lens, organized according to the three priority themes of the Education Council "rolling agenda", in order to raise an understanding of issues of employability, comparability and mobility. At the same time, I will argue that these issues are related to the "ways of thinking" portrayed earlier in this paper. My intention is to critically address some of the main topics that are being discussed, but some significant dimensions, most importantly e-learning, will not be systematically addressed in this inquiry.

In fact, the last European Councils have been consistent in repeating the need to build a "knowledge-based economy" or a "knowledge-based society" and have used these two terms interchangeably. The Stockholm European Council, for instance, stated in the section entitled "Education, training and skills", that, "Improving basic skills, particularly IT and digital skills, is a top priority to make the Union the most competitive and dynamic knowledge-based economy in the world" (2001, \10). One must not ignore the importance of the document eLearning: Designing tomorrow's education, approved in 2000 , as well as various follow-up decisions underlining how education and training will change under the conditions of the new information and communication technologies. Manuel Castell's perspective is fully adequate to understand European policies in this area: "The third major challenge [of the network society] is the installation of information-processing and knowledgegeneration capacity in every one of us - and particularly in every child. By this I obviously do not mean literacy in using the Internet in its evolving forms (this is

\footnotetext{
${ }^{8}$ The analysis focuses mainly on the following documents: Decisions establishing a "new generation of programmes" in the field of Education, Training, and Youth (January 2000); Report from the Commission Implementation of the White Paper Teaching and Learning: Towards the Learning Society (January 2000); Conclusions of the Lisbon European Council (March 2000); Working Paper Implementing Lifelong Learning for Active Citizenship in a Europe of Knowledge (March 2000); European Report on Quality of School Education (May 2000); Decisions of the Luxembourg Education Council (June 2000); Conclusions of the Feira European Council (June 2000); Decision on Guidelines for Member States' Employment Policies for the Year 2001 (January 2001); Report from the Commission on The Concrete Future Objectives of Education Systems (January 2001); Conclusions of the Stockholm European Council (March 2001).

${ }^{9} \mathrm{I}$ am quoting from the Communication from the Commission to the Council and the European Parliament The eLearning Action Plan - Designing tomorrow's education (COM/2001/0172, 28.03.2001).
} 
presupposed). I mean education. But in its broader, fundamental sense; that is, to acquire the intellectual capacity of learning to learn throughout one's whole life, retrieving the information that is digitally stored, recombining it, and using it to produce knowledge for whatever purpose we want. This simple statement calls into question the entire education system developed during the industrial era" (2001, pp. 277-278). Nevertheless, this "fundamental restructuring" deserves special attention, and it would be unreasonable to try to embrace it all in a single chapter.

\title{
Employability as a problem for each citizen
}

\begin{abstract}
New Europe-wide employment markets are emerging, driven by technological change and globalization. [...] The Commission has recently adopted a strategy [...] for the generalization of mobility and the acquisition of modern work skills at European level. This can now be built on, in a context of lifelong learning that sets great challenges to our traditional education and training systems. [...] Whatever forms this new method finally takes, the Commission will continue to play a key role of anticipation, awareness-raising and, critically, creating the mechanisms to put policies into practical effect and making the concept of lifelong learning an everyday reality (Lenarduzzi, 2001, p. 2).
\end{abstract}

The words of Domenico Lenarduzzi, Honorary Director-General (Education and Culture DG, European Commission), appear the beginning of issue 14 of the journal published by the European Commission, Le Magazine. They illustrate well the mainstream discourse about lifelong learning in European institutions: on the one hand, it redefines "employment" as a learning problem that should be solved by each individual; on the other hand, it creates the illusion that the "crisis of schooling" can be answered through a long life of education and training. The uses and abuses of this concept must be understood in the overall framework of providing a "magical solution" for some of the deeper concerns of European public opinion. Unemployment has been portrayed, namely by the media, as one of the main European problems - it is no surprise that the European Union places it at the heart of its agenda to eliminate "social exclusion".

It is essential to understand the social relevance of these issues, as European states need to deal with persistent high levels of unemployment and low rates of job creation. In all European guidelines for improving employability, the emphasis is placed on education and training for young people, as well as on lifelong learning. In fact, the concept of employability was recently reinvented as a way to link employment and education, or to see unemployment as a problem of uneducated people. The mobilization of this concept in political discourse entailed its transition from the social or economic sphere to the individual sphere. Therefore, it is easy to understand the decision to, "give higher priority to lifelong learning as a basic component of the European social model". It means that the crisis of the Welfare State (and/or of the European social model) should be solved by the citizens who are invited to become responsible for, "constantly updating their knowledge both in order 
to enhance employability, by acquiring skills attuned to developments in the nature and organization of work, and also in order to serve as a framework for the process of consolidating European citizenship" ${ }^{10}$.

This phenomenon brings with it a new relation of individuals to society and to work, a relation strongly mediated by education and training. As Nikolas Rose argues in Powers of Freedom, "The new citizen is required to engage in a ceaseless work of training and retraining, skilling and reskilling, enhancement of credentials and preparation for a life of incessant job seeking: life is to become a continuous economic capitalization of the self" (1999, p. 161). Thus, striving "to raise the level of knowledge and skills" and to prepare oneself for the "integration into a rapidly changing world of work" is a problem transferred to the individual sphere, with each citizen having the "responsibility" to solve it for him/herself. When the European Union set up a "new strategic goal": "to become the most competitive and dynamic knowledge-based economy in the world", the spread of lifelong learning was considered essential to the strategy to achieve this goal. Since then, documents issued by Brussels are systematically reiterating lifelong learning as, "the cornerstone of the knowledge-based society developing in Europe".

Ulrich Beck introduces a broader understanding of these issues, when he outlines fifteen points about "Living your own life in a runaway world". I want to highlight two of these points: "(Five) The other side of this obligation to be active is that failure becomes personal failure, no longer perceived as class experience in a culture of poverty. It goes hand in hand with forms of self-responsibility"; "(Six) Your own life - your own failure. Consequently, social crisis phenomena such as structural unemployment can be shifted as a burden of risk onto the shoulders of individuals" (2001, p. 167). That is why active citizenship, entrepreneurial culture, lifelong learning or reflexive life are part of the same reconfiguration of the self. Furthermore, we need to understand how the economics involve multiple overlapping discourses that include not only the economic, but also social, cultural and political dimensions. Peter Wagner, in his book about Theorizing Modernity (2001), explains that it would be misreading to talk about the notion of "entrepreneurial self" only as an economic injunction.

Relying on these perspectives, the European educational policies are creating new conceptions of the "reasonable" and "responsible" lifelong-learner and, at the same time, constructing an ideology that blames individuals who are unable to take care of their "own life", that is, their "own education". The new journeys of lifelonglearners in Europe are illustrated in the adoption of the "Europass training" established in 1999. Taken as a metaphor, this new passport permits the right to freely

\footnotetext{
${ }^{10}$ Commission communication of 12 November 1997: Towards a Europe of Knowledge.
} 
circulate around Europe following itineraries of training and job seeking. As the European Commission often recalls, "lifelong learning is not imposed from above" because it "needs to be provided as close to the learners as possible" and it depends on "personal motivation" (Le Magazine, 14, 2001, p. 3). At the same time, however, it is said that this is the only way out, the only possibility that individuals and societies have to face the "challenges of the future". European citizens are free to choose: between one alternative and the same, as if no other possibility could even be imagined.

\section{Comparability as a mode of governance}

The "Europeanization" of education has provoked the development of a strong feeling of "mutual accountability" between Ministers of Education. [...] The "politicization" of initiatives during the last few years in the field of education of injecting, "from the top", an acceleration and deepening of European co-operation might have been an answer to the more slow and more conservative development of Ministries and National education authorities (Hingel, 2001, pp. 18-19).

The words of Anders Hingel, head of the education policy unit at the European Commission, are extremely interesting for two main reasons. First, they construct an idea of "Europeanization" based on a logic of "mutual accountability" developed through an evaluation of, or a comparison between the national systems of education, using a series of indicators, outcomes, benchmarks or guidelines. Despite their differences, these concepts seem to be generated as making part of the same "discursive formation". Second, they define "politicization" as a reinforcement of decisions "from the top" - that is, directly by the Heads of State - breaking down resistance and inertia at the level of national authorities. Curiously enough, this perspective looks at the "educational space" as a field of expertise where the main objective is to reach obvious and consensual "outcomes".

In fact, a second dimension of Community action can be symbolized in the term "quality", but mainly in the way "quality" can be evaluated through comparable benchmarks and indicators. Indeed, it was this very word that enabled education, for the first time, to be included in a European Treaty in Maastricht. Today, it is one of the three subjects of the rolling agenda: "the development of quality education and training at all levels". If issues of employability are deeply embedded in ways of thinking driven by a media discourse, then issues of quality, carried out through politics of comparison, are impregnated by an expert-discourse that is developed on a worldwide scale. European policies are clearly moving to promote greater co-operation between the Member States, but also to achieve, "a strengthening of the political impact of the Community", in the field of education. In order to do this, two lines of action have been defined: "the dissemination of best practice and the enhancement of joint reflection" 
(2000, p. 10) $)^{11}$

With respect to best practice, which is abundantly mentioned in the European documents, the importance of its exchange, transfer and wide dissemination are all emphasized. Tackled implicitly, the concept of best practice gathers full force when it is mentioned in the same breath as the new technologies. The question is always approached in order to prepare "people for tomorrow's trades" and "in order to speed up changes in the education and training systems for Europe's move to a knowledge-based society" (2000, p. 3). "Change" is viewed as a technological device, and all texts are brimming with references to innovation, autonomy, flexibility, and entrepreneurial spirit in the new learning environment. In this sense, the European Commission differentiates between the industrial societies that, "set themselves the aim of ensuring that all citizens were properly versed in the three Rs", and the knowledge-based society that "implies that every citizen must be digitally literate" (2000, p. 4$)^{12}$.

In regarding joint reflection, it is very interesting to note the recent effort to build up, "a limited number of indicators or benchmarks for school standards to assist national evaluation of systems". In fact, the European Report on Quality of School Education (May 2000) clearly identifies, "the need to set quantifiable targets, indicators and benchmarks as a means of comparing best practice and as instruments for monitoring and reviewing the progress achieved", contributing to "educational policy making". The sixteen indicators cover four broad areas: attainment levels; educational success and transition; monitoring of school education; and educational resources and structures. The need for justification, admitted by the European Commission, is very interesting because it shows the types of problems that stand beyond this policy: "If Europe is to have a society of educated citizens - a society based on knowledge - all its countries must engage in a united effort to share information on national educational practices. This means telling it the way it is and not hiding any weakness, for the purpose of the exercise is to learn from one another, not to single out the good pupils from the bad" (Le Magazine, 14, 2001, p. 5). In fact, the question is not if it makes sense to organize a league table for schools or for nations, but to create an educational discourse - a discourse that includes indicators, outcomes, data and knowledge and becomes a regulating rule obliging everyone to refer back to it. Cohesion and configuration of policies are not achieved through sanctions, but through much more sophisticated and complex means. Voluntary participation by each national state, without any compulsory obligation, legitimizes these arguments. It is difficult to imagine how a national state could stand outside of this "playing field".

\footnotetext{
${ }^{11}$ Communication from the Commission: e-Learning - Designing tomorrow's education (2000).

${ }^{12}$ Communication from the Commission: e-Learning - Designing tomorrow's education (2000).
} 
One of the main objectives of this policy is to place "less emphasis on the control of input" and "greater emphasis on the control of output". The practices of audit and accountability seek "to provide policy makers with reference points" by rendering visible their "failures" and "success" in terms of indicators and standards that have been "commonly" defined and "freely" accepted. In this sense, they are governing principles that construct an educational policy that lies in specific forms of knowledge and expertise. This explains why the European Report on Quality of School Education (May 2000) clearly addresses the "challenge of data and comparability", claiming that its intention it is, "to create an open and positive climate for dialogue", and, "to provide a strong basis to learn from one another". These words sound strangely like the first statements by comparativists at the end of the $19^{\text {th }}$ century when the building of national mass education systems was at a crucial stage. But, we need to understand this "learning from one another" as a process of constructing a way of thought and action in the educational field.

Nevertheless, inside the European Union comparability is not organized through a traditional logic of borrowing or lending, nor is it even defined on the basis of the "international argument". Now, comparability is not only being promoted as a way of knowing or legitimizing, but mainly as a way of governing. That is why "comparing" must not be seen as a method, but as a policy. In fact, it is one of the most powerful modes of governance being administered in the European space. If one returns to the first and forgotten meanings of comparatio we are introduced to two main definitions: on the one hand, preparation, construction, combination and arrangement; on the other hand, comparison and relationship (cf. Oxford Latin Dictionary, 1969, p. 372). These different meanings are both present in the current strategies for restructuring the educational space. One of the main roles asked of those participating in the formation of a European space is to implement new educational policies: not through "laws", but through "governance". In this sense, one can argue that the expertdiscourse builds its proposals through "comparative strategies that tend to impose "naturally" similar answers in the different national settings.

\section{Mobility as a means to imagine European citizenship}

\footnotetext{
The first, and most obvious, of such mechanisms [to build an European identity] is education. We must introduce at all levels of the educational system of every country, some common elements, including the history, culture, and language of other countries in the programs of all schools (Castells, 2000).
}

My thoughts concerning "excesses" (of past and future) are constantly present in the analysis of the politics of citizenship in the European Union. A wide consensus seems to have been established regarding the role of education in the drive towards imagining and building this sense of belonging and identity. The European Union documents go even further in establishing a close "link between citizenship and 
education". In the report Learning for Active Citizenship (1998), a parallel is drawn up between "the introduction of mass public education [as] a key element in the emergence of modern citizenship" and the current importance of education given that "people need to be equipped to manage their lives as best they may in the mosaic-like cultural and political environments in which they find themselves".

In fact, this view of the link between education and citizenship is strongly influenced by an attempt to replicate the processes of nation building at a European level. The political vision that goes beyond this conception can still be illustrated by the famous words of Rousseau: "It is education that must give souls a national formation, and direct their opinions and tastes in such a way that they will be patriotic by inclination, by passion, by necessity" (cit. in Miller, 2000, p. 87). Reflecting on the construction of a European Demos, Lars-Erik Cederman says that "public education serves a central function not just as knowledge producer but also as a creator of citizens" (2001, p. 140). In truth, Brussels' effort to imagine a European identity can be compared to the fabrication of the nation-states in the $19^{\text {th }}$ century. Images put forward in some of the educational documents reflect an old fiction, that more closely resembles "an imaginary liturgy" (Lourenço, 1994). But, this is a misleading perspective. As, "democratic legitimacy within the EU cannot be obtained by modeling its institutions on those of the nation-state" (Bellamy \& Warleigh, 2001, p. 10), it is likewise useless to expect education systems to accomplish the same kind of missions as they did in the past.

Nowadays - namely in Europe - issues of citizenship are much more complex, both at individual and collective dimensions: on the one hand, the restructuring of memories is a cultural practice, "that forges narratives to instantiate visions of the citizen, the nation, and the new intra-national state of the European Union", and on the other hand, "old images of nation and self are dissociated from the new memories as people re-imagine themselves with a new collective narrative that relates to political projects bound to cultural identities" (Popkewitz, Lindblad \& Strandberg, 1999, pp. 52-53). Citizenship is moving from political and social arenas to the individual sphere, yet, at the same time, constructing new "territories" of affiliation and identity. That is why the documents issued by Brussels combine an attempt to replicate a traditional sense of "nationhood" at the European level with hybrid discourses permeated by expressions such as "diverse and overlapping values and identities", "variable geometry", "complexity and fluidity", "multiple identities", "flexible citizenship", and even with the statement, "that no value or behavior is prima facie excluded". One should realize that these politics of identity are provoking dynamics of qualification and disqualification, leading to the formation of a "new educated subject" that is included in the frame of the knowledge-driven society. Yet, at the same time, the frame excludes all the groups and individuals who do not possess the "skills" or the 
"attributes" required to play the knowledge-based game.

A decade ago, when a deeper attention to education was dedicated at the European level, leading to the approval of articles 126 and 127 of the Maastricht Treaty, the European dimension of education was the main focus. The Green Paper issued in 1993 reflected this perspective. Its intention was to "strengthen in young people a sense of European identity and to make clear to them the value of European civilization" and to "prepare young people to take part" in the development of the European Union. The presence of the "past" and the "future" is obvious in this way of thinking. The intended consequences were mainly expected to be in curriculum issues, incorporating "more Europe" in national guidelines in subjects such as history, geography or civics education. By the first half of the 1990s, a substantial amount of literature was promoting a strong rhetoric about citizenship in relation to curriculum and education. Adapting the words of Michel Foucault to this situation, from one of his last interviews, one could say that the ambition was for children from all countries to learn everything that makes a Nation entitled to ask someone to die for it (cf. Lotringer, 1996). In this case, the imagined community was the nation-Europe (Anderson, 1991).

This discourse proved to be inaccurate and unable to address European educational issues. Obviously, the tendency towards a European curriculum did not disappear in recent years, as it is clear in the current attempts, for instance, to build school textbooks impregnated with a European history or geography. Several groups of scholars around Europe are working together, creating a cooperative framework to address these topics. An important shift did take place over the last half-decade, moving from a "rhetorical" to a more "pragmatic" approach. I already discussed this shift, speaking about "employability" and "comparability", and this trend can easily be illustrated by numerous other objectives specified in the document The concrete future objectives of education systems (2001): "19. Information and communication technologies for everyone"; "23. Foreign language teaching"; "24. Increasing mobility and exchange"; etc. Instead of confronting cultural and national resistance, European educational policy is moving towards the construction of languages and methods aiming to undertake "common goals" and, thereby, taking similar approaches to the organization and evaluation of school systems.

For this purpose, the concept of mobility has been crucial. Not only does it contain an imaginary of past journeys and cultural travels, but it also suggests a sense of freedom and openness towards the future. The importance conceded to programs like Erasmus or Socrates is well established in several articles and books. At this point, it is not my intention to give further thought to these questions. I would, however, 
like to accentuate the symbolic role that they have been playing as part of wider movements towards the inscription of an experience of Europe in each citizen. Indeed, whether the focus is on markets and national states, or on debates over intergovernmental versus supra-national modes of authority within the European Union, one needs to recognize that scholarship has done little to comprehend what might be called the "itineraries of European integration". It is worthy to recall two ideas included in the presentation of a workshop with this same title ${ }^{13}$

\footnotetext{
${ }^{13}$ I am quoting the text from a workshop presentation on "Itineraries of European Integration", organised by the European Union Center - University of Wisconsin-Madison (April 2001), where a earlier version of this chapter was presented.
} 
: first, the opinion of anthropologist James Clifford who argues that all cultures are "traveling cultures" insofar that their members gain a sense of common history and shared values by movement and interaction with one another, and with "others" whose difference highlights connections with one's own; second, the suggestion that despite the modern nation state's insistence on territorial boundedness and culturalhistory "roots", a sense of nationality depends on movement and displacement, and the constant crossing not only of territorial but also social and cultural borders. A process of constructing identities depends on experiencing new journeys and itineraries, on living through borders and contact-zones, and on participating in groups and networks that bring together people from different countries. It is in this sense that mobility can be regarded as a means to imagine European citizenship.

\section{(IN)CONCLUSION:}

\section{FurTHER COMMENTS AND FUTURE DiRECTIONS}

In the remaining paragraphs it is my intention to address two issues: firstly, I will demonstrate the arguments raised throughout this chapter by using the Bologna process as an illustration, highlighting the actual processes and consequences of employability, competitiveness and mobility. I will then argue for the need to rethink the role and scope of research, namely comparative education research, with reference to the limits of current ways of thinking about Europe alluded to above.

\section{The Bologna Process as an Illustration of "Ways of Thinking" about Education in Europe}

The so-called Bologna process, initiated with the signing of two important declarations (Sorbonne, 1998, and Bologna, 1999), aims to establish a common "European Higher Education Area", wherein the policies and practices of tertiary level academic institutions across Europe will become more standardized or compatible with one another. In what follows, I use the Bologna process as a means to further illustrate Europe's regulatory ideal function, with its tendency toward defining common goals, similar strategies and identical policies. As will be revealed below, the overarching goals of the Bologna Declaration curiously coincide with the main tenets of European policy comprising the framework of this chapter.

The Bologna Declaration is somewhat of an anomaly in that EU Member States are autonomous with regard to the formulation of educational policies, and also because of the historical autonomy characteristic of the universities. It is interesting, however, that these two strong layers of autonomy do not present obstacles to the adoption of a "system of easily readable and comparable degrees", to the agreement 
upon an identical "degree structure based on two main cycles", to the establishment of a common "system of credits", or to the enforcement of "quality assurance systems" which are the hallmarks of the Bologna process ${ }^{14}$.

The strategic use of the word system in this document is intended to stress the existence of different "positions" that are arranged in order to form a unified "system", but it is built inside a rhetoric that celebrates the richness and diversity of cultures and languages. Indeed it would be unacceptable to draw a top-down policy that is not sensitive to the different traditions and perspectives. In fact, the strength of the Bologna process resides precisely in its bottom-up approach. Rather than laws or mandatory statutes, Bologna operates as a series of agreements and accords that are freely accepted and implemented. From this perspective, Foucault's concept of governmentality is crucial to our understanding of the reconfiguration of educational policies taking place within the European space. We need to ask how debates and strategies concerning the exercise of political power have delineated the proper relations in the general field of "conduct of conduct", engendering the emergence of programs of government. The main issue is to understand the rise of expert systems of knowledge: "The power of such expert knowledge is that it is not only knowledge. Ideas function to shape and fashion how we participate as active, responsible individuals" (Popkewitz, 1998, p. 5). That is to say - as Nikolas Rose puts it - we are inhabitants of regimes that act upon our own conduct in the proclaimed interest of our individual and collective well-being: "we are governed in our own name" (1999, p. 284).

The Bologna process, by constructing new ways of thinking about higher education, diffusing languages and imposing solutions for educational problems, serves a very real example of the phenomena alluded to in the first part of this chapter. Discussions taking place within universities are impregnated with a "sense of inevitability", as if it were no longer worthwhile to ask fundamental questions, because every institution will be moving along the same lines, independently of concerns they may have about this "inevitable" progression. The last report commissioned by the follow-up group of the Bologna process acknowledge the "unanimous support" that this process is receiving, even if it "has been conducted on a rather informal basis". The report indicates the numerous seminars and conferences that dealt with the Bologna Declaration, saying that these are "the best indicator of its impact on European higher education" and that it has "received a wider acceptance from the academic community than was possible to anticipate" 15 . Another report

\footnotetext{
${ }^{14} \mathrm{I}$ am quoting from the document Towards the European Higher Education Area-Communiqué of the meeting of European Ministers in charge of Higher Education in Prague on May 19th 2001.

${ }^{15}$ Furthering the Bologna Process - Report to the Ministers of Education of the signatory countries (Prague, May 2001). This
} 
prepared by Guy Haug and Christian Tauch for the Prague Conference, Trends in Learning Structures in Higher Education (2001), corroborates the "strong consensus on the core objectives of the process", revealing how it has been integrated into "the higher education agenda of all signatory countries" and evoked widespread interest even in non-signatory countries.

As alluded above, the Bologna Declaration has three general goals: employability, competitiveness, and mobility, which neatly coincide with the three ways of thinking that have been stressed in this chapter.

Employability is conceived as a goal that needs to be achieved by European universities. It means that the programs of study are to be organized in such a manner that they are "relevant to the European labor market". Intrinsic to this discourse is the concept of lifelong learning which serves as an endeavor to allow that "the education and training systems are open to new publics, and offer alternative learning paths to standard qualifications, as well as, a variety of non formal learning opportunities" ${ }^{\prime 16}$. In this sense, lifelong learning is conceived, both at individual and institutional levels, as a strategy that calls for a restructuring of the "labor market" and for a new relationship between learning and employment.

Competitiveness is understood as one of the main conditions to attract students from around the world. It is alleged that "quality assurance systems" and "accreditation" are prerequisites that need to be fulfilled. Readability of degrees, acceptance of qualifications in academic and professional terms, and clear information on the objectives and learning outcomes are identified as some of the strategies to guarantee "international competitiveness"17. Furthermore, the importance of "monitoring" the development of the Bologna process is asserted, namely through the gathering of comparable data.

Mobility is considered to be of one of the utmost objectives of the European Higher Education Area. The free movement of students is perceived as part of "active citizenship" as well as a form of experiencing different national traditions and cultures. At the same time, actions are taken to "foster the desired convergence". The tension between "autonomy" (leading to differentiation according to historical and cultural diversity), and "responsibility" (leading to a unified system of assessment and accountability), is well addressed in the first conclusion of the Convention of Higher Education Institutions, held in Salamanca, in March 2001: "Universities need new

report, prepared by Pedro Lourtie, and other documents related to the Bologna process can be found in several websites (e.g. www.esib.org).

${ }^{16}$ Furthering the Bologna Process, 2001, p. 16.

${ }^{17}$ Furthering the Bologna Process, 2001, pp. 5 and 9. 
freedom if they are to adjust rapidly to environmental changes and to new local, national and international partners. (...) Universities are not just requesting more freedom, however. They are also willing to accept the corresponding responsibility: they want to be held accountable for what they are doing and for how they use the freedom granted to them"18.

These goals are developed within the European space, creating new ways of thinking and talking about higher education. They are not only new words to describe facts and realities; they are new policies, built around a "planetspeak" that is organized around concepts that are being translated into most of the European languages: networks and governance, standards and accreditation, employability and accountability. It is interesting to observe that several of these concepts were imported from American institutions, where they have had a long tradition, carrying on specific meanings. Nevertheless, they are being mobilized as part of a European strategy that identifies its competitor in the global world: "The leading competitor is clearly the United States, as the main international provider of educational services"19.

Even if the European Union occupies a central position in this debate, it is important to reiterate that the signatories of the Bologna Declaration comprise already a total of 32 states; participating states are therefore not confined only to EU Member States. This influenced the European Ministers' decision to chose Prague for the location of the 2001 meeting, as "a symbol of their will to involve the whole of Europe in this process in the light of enlargement of the European Union" ${ }^{20}$. Even more so, the follow-up group of the Bologna process presents a broader sense of "unification" when asking if "there is a limit to the geographical reach of the European Higher Education Area"21. What we are witnessing here are changes in the relationship between States, universities, academic communities and employers. These dislocations and displacements are essential to our understanding of the construction of Europe as a new political entity. Sometimes we have the feeling of an "emptiness of meaning". It is a false impression. The meaning is being created through movement itself, in the way in which "ways of saying" are always "ways of seeing" the world, re-positioning our own beliefs, affiliations and identities.

\section{Education in Europe as a field of study}

Elaborating on the three ways of thinking previously discussed, it is my

\footnotetext{
${ }^{18}$ Cf. Furthering the Bologna Process, 2001, p. 28.

${ }^{19}$ Furthering the Bologna Process, 2001, p. 10.

${ }^{20}$ Towards the European Higher Education Area - Communiqué of the meeting of European Ministers in charge of Higher Education in Prague on May 19th 2001.

${ }^{21}$ Furthering the Bologna Process, 2001, p. 20.
} 
intention to underline some consequences for future research. My purpose is to start a theoretical and methodological discussion about the possibility of building new programs of research.

Firstly, I want to underline the importance of problematizing "Education in Europe" as an object of inquiry. It is true that there already exists an abundance of legal texts and policy-making books on this issue. These, however, tend to reproduce an "intentional language", created by the EU officialdom, and therefore lacking a theoretical or critical perspective. Rather, these existing texts are intertwined with ideas presented in the media, and constitute an amalgamation of discourses that asphyxiate alternative ways of thinking. My argument is that we need to deconstruct these "evidences" through intellectual thinking that crosses the boundaries of different disciplines in order to understand the new educational problems with which we are being confronted in Europe.

I acknowledge the fact that an important change is taking place, not only in the terms of increased opportunities for cooperation in Europe, but also in the development of research programs in the so-called European Research Area. At the same time, the literature that has been published to date provides us only with an incomplete and fragmented picture. That is why we need to re-encounter the coherence of intellectual thinking, and to rediscover the sense of shared reflection that renews the "intellectual commitment": not as a "prophecy", which has the right to map out paths and prescribe solutions, but as an analysis that questions the evidence, puts into doubt the ways of speaking and thinking, and rocks current habits (Foucault, 1994).

"Europe" is a fascinating subject for critical inquiry. Important social and cultural changes are taking place, but we currently lack both the words and the theories to fully comprehend it. Within the European Union, legal texts always look at the "added value of the Community action". Perhaps we can apply this metaphor to research, asking what is the explanatory layer specific to Europe. Without ignoring the importance of global approaches and local and cultural analyses, this focus will help us to define "Europe" as a field of study.

Secondly, I want to direct my attention to the importance of reinforcing theoretical approaches to comparative research in education. I will argue that this is the only way to avoid an international expert-discourse that circulates without being conceptually structured and historically located. This expert-discourse dissolves in the agenda set by the media, raising a doxa that obscures rather than illuminates. 
In the last two years important steps have been taking place Towards a European Research Area (title of a document approved by the European Commission, in 2000). This initiative is part of an effort to create a common approach to research, primarily through data collection and organization strategies with the aim of establishing "a common system of scientific and technical reference for the implementation of policies". There is a clear intention to stimulate comparative studies, which are deemed useful "to inform policy and practice". We are witnessing an attempt to build languages and methods, that do not contribute merely to "sharing and learning from one another", but which legitimize/de-legitimize systems of action and thought. Creating a uniformed way of talking constructs inclusions and exclusions and defines ways of talking that are not acceptable.

There is no doubt about the significance of those documents recently published, as a result of research projects organized under the auspices of the European Union. Nevertheless, most of these studies are mere juxtapositions of national cases, productions of typologies or other forms of classification, or displays of statistical data. Whereas occasionally the introductions and the conclusions of these texts attempt to raise some comparative analysis, they do so in a very superficial manner. For a long time, Comparative Education has been regarded as one of the less prestigious disciplines among educational sciences. Its current popularity is not based on a critique of the traditions of the field, or on the elaboration of new methods and theories, but rather on its ability to seize the opportunity to bring together scholars from different countries and to raise funding for research. To this extent, these studies are failing to build sound comparative approaches. It is my understanding that we need to invert this tendency if we are willing to constitute not only a "research area", but an "interpretive space", which does not constitute what can only be currently conceived of as "soft comparisons", but comparative research that is both theoretically and methodologically grounded.

Thirdly, I wish to advocate the need for a deeper historical perspective on European debates. Here, I am referring to an analysis of the present as part of historical practices that produce ways of thinking, acting, and feeling. In this sense, as T. Popkewitz, B. Franklin and M. Pereyra argue, history is not the movement toward some form of reliable representation, it is rather a part of the present: "A cultural history as a history of the present considers reason as a field of cultural practices that orders the ways that problems are defined, and possibilities and innovations sought" (2001, p. 4). My intellectual interest is in reconciling history and comparison, in order to avoid a parochial account of educational phenomena. The project of raising an understanding of the historical specificity of educational phenomena and simultaneously acknowledging the radical presence of the other(s) defines a new agenda for comparative research (Schriewer \& Nóvoa, 2001). 
European narratives are often filled with images of a "unitary past" directly connected with visions of an "inexorable future". Citizens and countries, from different regions of Europe, share this sense of having no escape, or other plausible alternatives. This fatalist fiction is the worst foundation upon which to base the discussion of Europe. That is why I advocate a historical perspective that reveals how problems have been constructed and reconstructed throughout time and space, in an effort to open up our intelligibility and understanding. The process of fabricating Europe, both as a make up and as a making, is far from being drawing to a close. That is why we need a European-wide public sphere - that is, "a network that gives citizens of all Member States an equal opportunity to take part in an encompassing process of focused political communication" (Habermas, 2001, p. 17) - that includes an intellectual and critical approach to social, cultural and educational problems.

Spatial metaphors are very present in Europeans debates. But as Göran Therborn recalls, "the space itself decides nothing" (2001, p. 87). New conceptions of the cosmopolitan citizen - constructivist, active, flexible, independent, autonomous, responsible - are being elaborated upon around the world: "the images of democracy and participation that are evoked are not a freedom separated from the problems of social administration and governing" (Popkewitz, 2001, p. 203). These conceptions bound the citizen to the "whole world", but through local and national affiliations. Europe is playing an important role in the governing of these different forms of identity. It is a role that needs to be elucidated through an intellectual inquiry, through a comparative-historical research.

\section{References}

Anderson, Benedict (1991). Imagined Communities. London: Verso.

Beck, Ulrich (2001). "Living your own life in a runaway world: Individualisation, globalisation and politics". In On the Edge - Living with Global Capitalism (Giddens, Anthony \& Hutton, Will, eds.). London: Vintage.

Bellamy, Richard \& Warleigh, Alex (2001). Citizenship Governance in the European Union. London and New York: Continuum.

Benjamin, Walter (1999). Illuminations. London: Pimlico.

Bennett, Oliver (2001). Cultural Pessimism - Narratives of Decline in the Postmodern World. Edinburgh: Edinburgh University Press.

Bhabha, Homi (1990). Nation and narration. London: Routledge. 
Bourdieu, Pierre (1996). Sur la télévision. Paris: Liber - Raisons d'agir.

Bourdieu, Pierre (2000). "La nouvelle vulgate planétaire”. Le monde diplomatique, no 554, May.

Brubaker, Rogers (1996). Nationalism reframed - Nationhood and the national question in the New Europe. Cambridge: Cambridge University Press.

Castells, Manuel (2000). European identity (Preliminary remarks). Lisbon: Paper prepared at the request of the Portuguese Presidency of the European Union.

Castells, Manuel (2001). The Internet Galaxy - Reflections on the Internet, Business, and Society. Oxford: Oxford University Press.

Cederman, Lars-Erik (2001). "Nationalism and Bounded Integration: What it would take to construct a European Demos". European Journal of International Relations, 7 (2), pp. 139-174.

Debord, Guy (1994). The society of the spectacle. New York: Zone Books.

Eder, Klaus \& Giesen, Bernhard (2001). European Citizenship between National Legacies and Postnational Projects. Oxford: Oxford University Press.

European Commission, Le Magazine, $\mathrm{n}^{\circ}$ 14, 2001.

Foucault, Michel (1994). Dits et écrits. Paris: Gallimard.

Gellner, Ernest (1983). Nations and Nationalism. Ithaca, N.Y.: Cornell University Press.

Green, Andy; Wolf, A. \& Leney, T. (1999). Convergence and divergence in European Education and Training Systems. London: Institute of Education - University of London.

Habermas, Jürgen (2001). “Why Europe needs a Constitution”. New Left Review, 11, pp. 5-26.

Hantrais, Linda (2000). Social Policy in the European Union. London: Macmillan Press, 2nd edition.

Hardt, Michael \& Negri, Antonio (2000). Empire. Cambridge, MA: Harvard University Press.

Haug, Guy \& Tauch, Christian (2001). Trends in Learning Structures in Higher Education. Followup Report prepared for the Salamanca and Prague Conferences of March/May 2001 (www.unige.ch/eua).

Hingel, Anders (2001). Education policies and European governance. Brussels: European Commission - Directorate-Generale for Education and Culture. 
Hobsbawm, E.J. (1990). Nations and nationalism since 1780. Cambridge: Cambridge University Press.

Hodson, Dermot \& Maher, Imelda (2001). "The open method as a new method of governance: The case of soft economic policy co-ordination". Journal of Common Market Studies, 39 (4), pp. 719-746.

Lenarduzzi, Domenico (2001). "Editorial”. Le Magazine, n 14, p. 2.

Lotringer, Sylvère, ed. (1996). Foucault Live - Collected Interviews, 1961-1984. New York: Semiotext(e).

Lourenço, Eduardo (1994). Nós e a Europa ou as duas rã̃ões. Lisboa: Imprensa Nacional.

Meyer, John (1999). Globalization and the Curriculum: Problems for theory in the Sociology of Education. Lisbon: Lecture given at the University of Lisbon.

Miller, David (2000). Citizenship and National Identity. Cambridge: Polity Press.

Nóvoa, António (2000). "The restructuring of the European Educational Space". In Educational Knowledge - Changing Relationships between the State, Civil Society, and the Educational Community (Popkewitz, Thomas, ed.). New York: Suny Press, pp. 31-57.

Nóvoa, António (2001). "Texts, Images, and Memories: Writing new histories of education". In Cultural History and Education: Critical studies on knowledge and schooling (Popkewitz, Thomas; Franklin, Barry \& Pereyra, Miguel, eds.). New York: Routledge Falmer, pp. 45-66.

Peterson, John (2001). "The choice for EU theorists: Establishing a common framework for analysis". European Journal of Political Research, 39, pp. 289-318.

Popkewitz, Thomas (1998). Struggling for the Soul: The Politics of Schooling and the Construction of the Teacher. New York: Teachers College Press.

Popkewitz, Thomas; Lindblad, Sverker \& Strandberg, Johanna (1999). Review of Research on Education Governance and Social Integration and Exclusion. Uppsala: Department of Education Uppsala Reports of Education 35.

Popkewitz, Thomas, ed. (2000). Educational Knowledge. New York: Suny Press.

Popkewitz, Thomas (2001). "Rethinking the political: Reconstituting national imaginaries and producing difference in the practices of schooling". The International Journal of Inclusive Education, vol. 5, n 2/3, pp. 179-207.

Popkewitz, Thomas; Franklin, Barry \& Pereyra, Miguel, eds. (2001). Cultural history an 
education: Critical studies on knowledge and schooling. New York and London: RoutledgeFalmer.

Rabkin, Jeremy (2001). Why supra-national citizenship is a bad idea. Lisbon: Paper presented at the Calouste Gulbenkian Conference (October, 24-26).

Roberts, Ivor \& Springer, Beverly (2001). Social Policy in the European Union. London: Boulder.

Roscoe, J.; Marshall, H. \& Gleeson, K. (1995). "The Television Audience: A reconsideration of the taken-for-granted terms active, social and critical'. European Journal of Communication, 10 (1).

Rose, Nikolas (1999). Powers of freedom. Cambridge: Cambridge University Press.

Schmitter, Philippe (2001). What is there to legitimize in the European Union... and how might this be accomplished? Lisbon: Paper presented at the Calouste Gulbenkian Conference (October, 2426).

Schriewer, Jürgen \& Nóvoa, Antonio (2001). "History of Education". In International Encyclopaedia of Social and Bebavioural Sciences. Oxford: Elsevier, vol. 6, pp. 4217-4223.

Sisson, Keith \& Marginson, Paul (2001). Soft Regulation - Travesty of the Real Thing or New Dimension? Sussex: ESRC “One Europe or Several” Programme - Working paper 32/01.

Sisson, Keith \& Marginson, Paul (2001a). Benchmarking and the "Europeanisation" of social and employment policy. Sussex: ESRC "One Europe or Several” Programme - Briefing note 3/01.

Smith, Anthony (1991). National identity. Reno: University of Nevada Press.

Smith, Anthony (2000). The Nation in History - Historiographical debates about ethnicity and nationalism. Hanover: University Press of New England.

Therborn, Göran (2001). "Into the $21^{\text {st }}$ century - The new parameters of global politics". New Left Review, 10, pp. 87-110.

Wagner, Peter (2001). Theorizing Modernity - Inescapability and Attainability in Social Theory. London: Sage.

Wallace, Helen (2001). "The Changing Politics of the European Union: An Overview". Journal of Common Market Studies, 39 (4), pp. 581-594.

\section{European Union Documents}

1993 - Green Paper European Dimension of Education. 
1995 - White Paper Teaching and Learning: towards the Learning Society.

1997 - Study Group on Education and Training Accomplishing Europe through Education and Training.

1997 - Communication from the Commission Towards a Europe of Knowledge.

1998 - Report from the Commission Learning for active citizenship: A significant challenge in building a Europe of knowledge.

2000 - Lisbon European Council: Presidency Conclusions.

2000 - European Report on Quality of School Education.

2000 - Communication from the Commission e-Learning - Designing Tomorrow's Education.

2000 - Decision from the Commission - Towards a European Research Area.

2001 - Stockholm European Council: Presidency Conclusions.

2001 - White Paper European Governance.

2001 - Report from the Commission The concrete future objectives of education and training systems.

2001 - Communication from the Commission The eLearning Plan - Designing tomorrow's education.

2001 - Furthering the Bologna Process - Report to the Ministers of Education of the signatory countries (Rapporteur: Pedro Lourtie).

2001 - Communiqué of the meeting of European Ministers in charge of Higher Education in Prague on May 19th 2001 - Towards the European Higher Education Area. 